\title{
KASPAR HAUSER UM DESCONHECIDO: NA TRÍADE ENTRE COMUNICAÇÃO, OLHAR INTERACIONISTA E VISÃO ANTROPOLÓGICA
}

\section{ARTIGO ORIGINAL}

ABRUNHOSA, Juremir Costa ${ }^{1}$

ABRUNHOSA, Juremir Costa. kaspar Hauser um desconhecido: Na tríade entre comunicação, olhar interacionista e visão antropológica. Revista Científica Multidisciplinar Núcleo do Conhecimento. Ano 05, Ed. 08, Vol. 10, pp. 125-131. Agosto de 2020. ISSN: 2448-0959, Link de acesso: https://www.nucleodoconhecimento.com.br/comunicacao/kaspar-hauser

\section{RESUMO}

Este estudo tem por desenho norteador estabelecer uma discussão ao auditório sobre o filme de kaspar Hauser, em perspectiva do actante principal ser um desconhecido para uma sociedade Eurocêntrica, numa abordagem de uma tríade entre comunicação, olhar interacionista e visão antropológica, que geram a identificação de aspectos problemáticos na apropriação do conhecimento e da linguagem, na intercessão de uma trama no século XIX de confinamento social em construção da formação do ser humano. Criando um paradoxo de um personagem que embora tenha se mostrado único, estranho e desigual na possibilidade de ampliação da diversidade no mundo visto diferente, ele também desenvolveu a capacidade inaceitável de reproduzir a não aceitação "do outro", do real, concreto e material, para a época. Este filme reflete uma sociedade baseada no racionalismo positivista, em que o processo

\footnotetext{
${ }^{1}$ Especialização em Antropologia - Universidade Cândido Mendes; Enfermagem e Obstetrícia - Universidade Gama Filho; Teologia - Universidade Metodista de São Paulo " cursando sexto período".
} 
de comunicação, humanização e socialização não é o resultado natural da nossa espécie, mas o resultado do aprendizado social e da identificação do grupo.

Palavras-chaves: Kaspar Hauser, processo social, comunicação, visão antropológica, processo interacionista.

\section{INTRODUÇÃO}

A Antropologia está muito preocupada com o contexto do objeto, em suas dimensões culturais e sociais de pesquisas, a partir da linguagem, comunicação e autoexpressão humana, seja ela oral, escrita e artística, assim proporcionando ao mundo uma representatividade e um sentido atribuído, enquanto simbolização da cultura e transmissão da tradição, numa investigação de que a linguagem reflete-se na construção identitária influenciando diretamente aos indivíduos nos grupos.

Nesse sentido, a motivação essencial deste estudo abarca-se na ampliação e clareza, a respeito sobre a comunicação humana, dentro de uma vertente em que cada pessoa é uma pessoa completamente única (devido à sua experiência e história de vida).

Para isso, será discutido o enigma de Kaspar Hauser, numa trama retratada na época do século XIX quando a resposta do padrão eurocêntrico de comportamento se encaixava num "normal" social e cultural. Permitindo identificar e compreender o que aconteceu com o protagonista na trama, ou seja, como o comportamento individual e a estrutura social do indivíduo pode ser confrontados pela antropologia linguística.

\section{AS HIPÓTESES DA TRAMA}

E inicialmente neste caminho proposto, o filme "O enigma de Kaspar Hauser trata sobre a figura enigmática de (..), uma criança abandonada em Nuremberg, Alemanha, no século XIX“ (PIRES,2016), Existem três teorias que (RAFFAELLI, 2014, p. 10, 14) argumenta sobre a gênese do filme :

1. Na primeira hipótese é sempre ventilado a perspectiva de fraude, em que o actante principal poderia ter sido um mendigo andarilho que se aproveitou do 
contexto criado com objetivo expresso de minimizar a sua condição de vulnerabilidade, além disso, o autor cita Feuerbach, em que Kaspar poderia ter sido um cavaleiro disfarçado, e Delorme que fala da probabilidade influenciadora por outros casos de reivindicações de pretendentes a nascimento nobre, mas todas as possibilidades giram em torno do eixo que justifica a ideia em burlar a identidade real;

2. A segunda teoria é contada como se ele tivesse sido um príncipe, ou seja, foi herdeiro da Filha de Napoleão sendo substituído por um filho de um jardineiro ou até Ludwig I (1786-1868), como o responsável pelo encarceramento de Kaspar e facilitador da sua morte, entretanto, todos esses Fenômenos conspiratórios foram muito bem-criados e são convincentes em muitos aspectos, apesar de pontos conflitantes;

3. E a última argumentação é a chamada teoria do acaso alicerçada em modelo psicológico temporal persistente que contraria a face de um impostor, devido a todas as pressões e congruência de forças ameaçadoras que atentavam a sua vida.

\section{O PERCURSO DO ENIGMA}

A trama é baseada no confinamento que o personagem teria passado, submetido a pão e água em um calabouço, atendido por um homem cujo rosto ele nunca via. $\mathrm{O}$ cenário que se estabelece ocorre num contexto Eurocêntrico de modelo social, "dito desenvolvido" a ser alcançado, e se inicia com uma aparição de um jovem rapaz com cerca de 16 anos, "(...) quando chegou à praça da comunidade, trazia consigo uma carta, um livro com orações, um terço e algumas folhas de ouro". Conforme (SACHETE; BRISOLARA, 2013, p. 117). E ainda, "(...) o garoto não entendia nada do que the diziam; sabia falar apenas uma frase: "quero ser cavaleiro" e não sabia andar direito. Parecia um menino dentro de um corpo adolescente. Seu comportamento estranho (...)" (SABOYA, 2001, p. 02).

Portanto, para Saussure, que é citado por (SACHETE; BRISOLARA, 2013) o signo linguístico é a associação que fazemos em nosso cérebro, a partir do "significante" que pode ser definido como uma a imagem acústica, que dará leitura a um " 
significado", na construção de um conceito, e por isso que (BAGNO, 2016, p .03) afirma que "A linguagem está inscrita dentro do cérebro humano, nós não temos acesso direto a ela, só a seus produtos". Assim formando, a chamada cultura material que pode ser "(...) concebida como constituída por uma série de signos metacríticos, signos cujo sentido mantém-se radicalmente disperso por uma cadeia aberta de significantes-significados", de acordo (FUNARI, 1999, p.05).

Por conseguinte, (CLETO; DE ALMEIDA, 2016, p. 170) cita Blikstein, em que podemos concluir "[...] a realidade extralinguística não seria decisiva para a articulação do significado dos signos; o que importa é que a relação entre símbolo e referência seja correta e até lógica". E o mesmo autor afirma que o personagem foi levado para a prisão, por causa da abertura de um processo local , em que após inúmeros testes descobriram que Kaspar Hauser não sabia falar e nem escrever, nada além que foi treinado. Portanto "Os indivíduos daquela sociedade tentavam encontrar explicações para a sua falta de conhecimento acreditando, por vezes, que se tratava de loucura ou de um estado de selvageria, ou ainda algo curioso, um verdadeiro mistério a ser desvendado". (CLETO; DE ALMEIDA, 2016, p.168 )

Nesse sentido (DAMERGIAN, 2009, p. 254) cita Jones "(...) que a deformação da percepção da cultura faz com que a pessoa perceba como "errado", "inferior", " pobre", "impróprio", "anormal" simplesmente aquilo que é diferente (...)".

A sociedade da época indignada com o processo diferente de comunicação de Kaspar Hauser, pois, não falava, e nem reconhecia os gestos e expressões humanas que expressavam a realidade. "Na verdade tudo the é estranho: as dimensões, os movimentos, a perspectiva, o pensamento, a fala" de acordo (SABOYA, 2001, p.04), sendo observado uma falta sistemática de compreensão da realidade exterior e do mundo, desse modo (SACHETE; BRISOLARA, 2013, p. 117) cita Vygotsky explicando o porquê, pois "Essa compreensão de mundo só é possível se o desenvolvimento da criança for mediado por outro, fazendo com que ele, passe da condição de ser biológico para um ser cultural." "Kaspar Hauser, entretanto, nos levaria a questionar o inatismo, pois os seus 'enigmas' de cognição e compreensão do mundo estão a indicar 
que a percepção depende, sobretudo, de uma construção e de uma prática social.", Blikstein citado mais uma vez por (CLETO; DE ALMEIDA, 2016, p.168)

O filme desenrola numa época positivista, evolucionista e desenvolvimentista, que tinha um modelo de civilização a ser alcançado, de forma individual, cultural e social, afim de ajudar os "diferentes" atingirem graus mais evolutivos. (Op. Sic.)

Com o passar do tempo no processo de socialização Kaspar começou a ter uma comunicação básica com outros seres humanos. Entretanto a forma de Hauser lidar com o mundo que o cercava era muito particular e isso se tornou um problema. E Por que seria um recorte temático problemático?

O paradoxo dentro do enigma ocorre, pois, apesar de o personagem apresentar se como o diferente, estranho e desigual em inúmeras possibilidades ampliadoras antropológicas da diversidade no trajeto do reconhecimento do plural, ao mesmo tempo, o mundo era diferente para Kaspar, então ele também desenvolveu a capacidade de reprodução da não aceitação "do outro", "dos ditos", real, concreto e material, para a época.

Após sua socialização, Feuerbach (1996, p.144) o descreve como não possuindo "um lampejo de fantasia, incapaz de fazer qualquer tipo de brincadeira ou de entender mesmo uma forma metafórica de falar". A ausência de espelho que gerou sua carência do imaginário marcou a sua personalidade de modo duradouro, sendo incapaz de metaforizar e de entender ou formular um chiste. Por isso, Feuerbach (1996, p.145) descreveu seu temperamento "como um lago plácido, espelhado, iluminado por uma lua cheia no silêncio da noite". Seco e assexuado, não tinha como entender o desejo feminino, só podendo pensar numa esposa como uma espécie de empregada-chefe, que poderia ser dispensada se cometesse algum erro. Mais uma vez, temos que a única diferenciação quanto ao gênero que Kaspar conhecia era com relação às funções sociais e que a sexualidade feminina the era estranha.(RAFFAELLI, 2014, p.23).

Hauser sofreu um atentado recebendo um ferimento que resultou em sua morte. Entretanto, ele continuou povoando no imaginário coletivo como um grande enigma. 


\section{CONCLUSÃO}

Devido ter ficado por um período prolongado isolado da humanidade não houve um desenvolvimento das suas atividades cognitivas num padrão neurológico, com inúmeras hipóteses de haver deformação em área encefálica da compreensão. Entretanto, devido a sua condição de confinamento ocorreu cerceamento a efetivação de participação no processo natural de interação aos fenômenos sociais, por meio da comunicação, linguagem e padrões de comportamentos culturais, com a consequência da compreensão do mundo e do outro, dentro das mesmas perspectivas de linguagem.

O objeto que enxergamos passam por uma (membrana) histórica, cultural e social, afim de darmos uma nomeação alicerçada aos processos internalizados durante a vida, em confronto, o filme levanta o conflito, de que mesmo com uma razoável e básica capacidade de comunicação, o personagem principal não enxergava os objetos com as dimensões de realidade em consequência da aplicabilidade dos filtros socioculturais contextualizados.

O filme leva a reflexão de uma sociedade fundamentada no racionalismo positivista, em que o processo de comunicação, humanização e socialização não são uma consequência natural da nossa espécie, mas sim, um resultado de aprendizagem social em identificação ao grupo.

Na lápide de Kaspar Hauser existe a inscrição "Hic occultus occultu uccisus est.", que traduzido para a Língua Portuguesa significa "Aqui jaz um desconhecido assassinado por um desconhecido" refletindo muito bem a sua trajetória.

\section{REFERÊNCIAS}

BAGNO, Marcos. O que é Linguística? São Paulo, ano 2016. Disponívelem<http s://www.parabolablog.com.br/index.php/blogs/o-que-e-linguistica> Acesso em: 29 abr. 2020. 
CLETO, E.A.T. ; ALMEIDA , C.R. de. O enigma de Kaspar Hauser e a importância da Linguagem no socializador. Tocantis. V.5, n. 2. p. 166-178, 2016 Disponível em <https://www.academia.edu/40644106/O_ENIGMA_DE_KASPAR_HAUSER_E_A_ IMPORT\%C3\%82NCIA_DA_LINGUAGEM_NO_PROCESSO_SOCIALIZADOR> Acesso em: 29 abr. 2020.

DAMERGIAN, Sueli. Migração e referenciais identificatórios: linguagem e preconceito. Psicol. USP, São Paulo, v. 20, n. 2, p. 251-268, June 2009 . <http://www.scielo. br/scielo.php?script=sci_arttext\&pid=S010365642009000200007\&lng=en\&nrm=iso >. Accesso em : 03 Mai 2020.

FUNARI, Pedro Paulo Abreu. Lingüística e arqueologia. DELTA, São Paulo, v. 15, n. 1, p. 00, Feb. 1999 . Available from <http://www.scielo.br/scielo.php? script=sci_arttext\&pid=S0102-44501999000100008\&lng=en\&nrm=iso > Accesso em : 03 Mai 2020.

KOTTAK, Conrad Phillip Espelho para a humanidade [recurso eletrônico] : uma introdução concisa à antropologia cultural / Conrad Phillip Kottak ; tradução: Roberto Cataldo Costa ; revisão técnica: Carlos Caroso. - 8. ed. - Dados eletrônicos. - Porto Alegre : AMGH, 2013

OLIVEIRA, Carolina Bessa Ferreira de . Fundamentos da Antropologia e Sociologia / Carolina Bessa Ferreira de Oliveira, Débora Sinflório da Silva Melo, Sandro Alves de Araujo; [revisão técnica: Gustavo da Silva Santanna]. - Porto Alegre: SAGAH, 2018.

PIRES, Aline Jéssica. Kaspar Hauser e o enigma da linguagem São Paulo, ano 2016 Disponível em <https://www.blogs.unicamp.br/linguistica/2016/09/09/109/> Acesso em: 29 abr. 2020.

RAFFAELLI , Rafael . A inércia do imaginário , FPolis, ano 2004, n 59. Disponívelem <h ttps://periodicos.ufsc.br/index.php/cadernosdepesquisa/article/download/1734/4441 > Acesso em: 29 abr. 2020. 
RASTIER, François. Tem a linguagem uma origem?. Rev. bras. psicanál, São Paulo , v. 43, n. 1, p. 105-117, mar. 2009 . Disponível em <http://pepsic.bvsalud.org/sci elo.php?script=sci_arttext\&pid=S0486-641X2009000100013\&lng=pt\&nrm=iso $>$. Acesso em: 03 maio 2020.

RECHENBERG, Fernanda. Licenciatura em Ciência sociais: Antropologia I. Alagoas, UFA, 2017.

SABOYA, Maria Clara Lopes. O ENIGMA DE KASPAR HAUSER (1812?-1833): UMA ABORDAGEM PSICOSSOCIAL. Psicol. USP, São Paulo , v. 12, n. 2, p. 105-117, 2001 Available from<http://www.scielo.br/scielo.php?script=sci_arttext\&pid=S010365642001000200 007\&lng=en\&nrm=iso $>$.Acesso em: 29 abr. 2020.

SACHETE, S. ; BRISOLARA, V.S. Análise Vigoskyana do filme de Kaspar Hauser Santa Cruz do Sul, v. 38, n. 65, 2013. Disponível em $<$ https://online.unisc.br/seer/index. php/signo/article/view/4180> Acesso em: 29 abr. 2020.

Enviado: Julho, 2020.

Aprovado: Agosto, 2020. 